\title{
Intrinsic Dynamics of Quantum-Dash Lasers
}

\author{
Cheng Chen, Student Member, IEEE, Yang Wang, Member, IEEE, Hery Susanto Djie, Member, IEEE, Boon S. \\ Ooi, Senior Member, IEEE, Luke F. Lester, Senior Member, IEEE, Thomas L. Koch, Fellow, IEEE, \\ and James C. M. Hwang, Fellow, IEEE
}

\begin{abstract}
Temperature-dependent intrinsic modulation response of InAs/InAlGaAs quantum-dash lasers was investigated by using pulse optical injection modulation to minimize the effects of parasitics and self-heating. Compared to typical quantum-well lasers, the quantum-dash lasers were found to have comparable differential gain but approximately twice the gain compression factor, probably due to carrier heating by free-carrier absorption, as opposed to stimulated transition. Therefore, the narrower modulation bandwidth of the quantum-dash lasers than that of quantum-well lasers was attributed to their higher gain compression factor. In addition, as expected, quantum-dash lasers with relatively long and uniform dashes exhibit higher temperature stability than quantum-well lasers. However, the lasers with relatively short and nonuniform dashes exhibit stronger temperature dependence, probably due to their higher surface-to-volume ratio and nonuniform dash sizes.
\end{abstract}

Index Terms-Differential gain, microwave modulation, optical modulation, quantum wells, quantum wires, semiconductor lasers.

\section{INTRODUCTION}

Q UANTUM-DASH lasers are promising alternatives to quantum-well lasers in long-wavelength fiber-optic communication systems. Since their invention a decade ago [1], they have demonstrated many advantageous properties, including temperature stability [2], low noise [3], broad gain [4], and broad emission [5]. However, the modulation bandwidth of quantum-dash lasers is generally narrower than that of quantumwell lasers [6], [7].

Manuscript received August 10, 2010; revised October 4, 2010, and November 12, 2010; accepted December 22, 2010. Date of publication February 17, 2011; date of current version October 5, 2011. This work was supported in part by the U.S. National Science Foundation under Grant 0725647 , in part by the Army Research Laboratory under Cooperative Agreement W911NF07-2-0064, and in part by the Commonwealth of Pennsylvania, Department of Community and Economic Development under Pennsylvania Infrastructure Technology Alliance.

C. Chen is with RF Micro Devices, Inc., Greensboro, NC 27409 USA (e-mail: eric.chen2@rfmd.com).

Y. Wang is with OptiComp Corp., Zephyr Cove, NV 89448 USA (e-mail: ywang81@ieee.org)

H. S. Djie is with JDS Uniphase Corp., San Jose, CA 95134 USA (email: hery@ieee.org).

B. S. Ooi is with the Division of Physical Science and Engineering, King Abdullah University of Science and Technology, Thuwal 23955-6900, Saudi Arabia (email: bsooi@ieee.org).

L. F. Lester is with the Center for High Technology Materials, University of New Mexico, Albuquerque, NM 87106 USA (e-mail: luke@ chtm.unm.edu).

T. L. Koch is with the Electrical and Computer Engineering Department and the Center for Optical Technologies, Lehigh University, Bethlehem, PA 18015 USA (e-mail: tlkoch@lehigh.edu).

J. C. M. Hwang is with Compound Semiconductor Technology Laboratory, Lehigh University, Bethlehem, PA 18015 USA (email: jh00@lehigh.edu).

Digital Object Identifier 10.1109/JSTQE.2010.2103373
Similar to quantum-wire and quantum-dot lasers, quantumdash lasers are more quantum confined than quantum-well lasers. The narrower modulation bandwidth of these highly quantum-confined lasers has been attributed to various limiting mechanisms, such as carrier capture, relaxation and escape [8], state filling [9], and inhomogeneous broadening [10]. To overcome these limitations, several approaches were proposed, including tunnel injection, $p$-doping of the active region [11], improved quantum-dash growth, and waveguide optimization [12]. These approaches improved the modulation bandwidth of quantum-dash lasers to greater than $10 \mathrm{GHz}$, but it still fell short of that of quantum-well lasers [13].

Further improvement of the modulation bandwidth of quantum-dash lasers hinges on understanding the effect of quantum confinement on dynamic laser properties, such as differential gain, gain compression factor, and temperature dependence. In particular, unlike previous studies [14], [15] on gain compression in quantum-dash lasers, this paper uses a pulse optical injection modulation technique to analyze the intrinsic dynamics of two types of quantum-dash lasers without self-heating or parasitic impedances. The first type of lasers has long dashes and resembles quantum-wire lasers, and the second type of lasers has short dashes and resembles quantum-dot lasers. Their intrinsic dynamics show that the differential gain of the quantum-dash lasers is comparable to that of a typical quantum-well laser, but the gain compression factor of the quantum-dash lasers is approximately twice that of the quantum-well laser. Therefore, the modulation bandwidth of the quantum-dash lasers appears to be mainly limited by the gain compression factor. In addition, while the long-dash laser exhibits superior temperature stability than the quantum-well laser, the short-dash laser exhibits comparable or even inferior temperature stability than the quantum-well laser. Since quantum-dot lasers have exhibited [16] superior temperature stability of the dynamic properties than quantum-well lasers, the inferior temperature stability of the present short-dash laser is attributed to its nonuniform dash sizes. These differences in modulation bandwidth and temperature dependence are analyzed in detail in the following.

\section{LASER STRUCTURES}

Table I lists the structures and fundamental properties of the three types of lasers used in the present investigation, which emphasizes qualitative comparison of intrinsic dynamics rather than quantitative comparison of performance merits. First, a quantum-well laser serves as the reference. Although the laser is not specially designed for high-speed performance, it exhibits typical characteristics of long-wavelength quantum-well lasers, such as a modulation efficiency of 
TABLE I

STRUCTURES AND PROPERTIES OF THREE TyPeS OF LASERS INVESTIGATED

\begin{tabular}{|c|c|c|c|}
\hline Heterostructure & InGaAs/InGaAsP & \multicolumn{2}{|c|}{ InAs/InAlGaAs } \\
\hline Quantum Confinement & Well & Long Dash & Short Dash \\
\hline Number of Layers & 5 & 5 & 4 \\
\hline Density & --- & \multicolumn{2}{|c|}{$10^{10} \mathrm{~cm}^{-2}$} \\
\hline Size & $5.5 \mathrm{~nm}$ & $300 \times 25 \times 5 \mathrm{~nm}^{3}$ & $(20-75) \times 18 \times 3 \mathrm{~nm}^{3}$ \\
\hline Cavity Length & $400 \mu \mathrm{m}$ & $400 \mu \mathrm{m}$ & $340 \mu \mathrm{m}$ \\
\hline Ridge Width & $3 \mu \mathrm{m}$ & $4 \mu \mathrm{m}$ & $3 \mu \mathrm{m}$ \\
\hline Threshold Current & $22 \mathrm{~mA}$ & $44 \mathrm{~mA}$ & $200 \mathrm{~mA}$ \\
\hline Character. Temperature* & $68 \mathrm{~K}$ & $140 \mathrm{~K}$ & $54 \mathrm{~K}$ \\
\hline Emission Wavelength & $1600 \mathrm{~nm}$ & $1565 \mathrm{~nm}$ & $1615 \mathrm{~nm}$ \\
\hline Emission Bandwidth & $<10 \mathrm{~nm}$ & $\sim 10 \mathrm{~nm}$ & $>10 \mathrm{~nm}$ \\
\hline Slope Efficiency & $0.35 \mathrm{~W} / \mathrm{A}$ & $0.17 \mathrm{~W} / \mathrm{A}$ & $0.09 \mathrm{~W} / \mathrm{A}$ \\
\hline Internal Loss & $17 \mathrm{~cm}^{-1}$ & $14 \mathrm{~cm}^{-1}$ & $18 \mathrm{~cm}^{-1}$ \\
\hline Optical Confine. Factor & 0.05 & 0.03 & 0.02 \\
\hline Active Volume & $3.3 \times 10^{-11} \mathrm{~cm}$ & $3.0 \times 10^{-11} \mathrm{~cm}^{3}$ & $1.2 \times 10^{-11} \mathrm{~cm}^{3}$ \\
\hline Group Velocity & $8.3 \times 10^{9} \mathrm{~cm} / \mathrm{s}$ & $8.6 \times 10^{9} \mathrm{~cm} / \mathrm{s}$ & $8.2 \times 10^{9} \mathrm{~cm} / \mathrm{s}$ \\
\hline Mirror Loss & $28 \mathrm{~cm}^{-1}$ & $25 \mathrm{~cm}^{-1}$ & $33 \mathrm{~cm}^{-1}$ \\
\hline Photon Lifetime & $2.6 \mathrm{ps}$ & $3.0 \mathrm{ps}$ & $2.4 \mathrm{ps}$ \\
\hline Reference & {$[17]$} & {$[15]$} & {$[18]$} \\
\hline
\end{tabular}

*Characteristic temperature extracted from $-50^{\circ} \mathrm{C}$ to $40^{\circ} \mathrm{C}$.

$\sim 1 \mathrm{GHz} / \mathrm{mA}^{1 / 2}$ and a $K$ factor of $\sim 0.3$ ns (see Section IV). The laser is based on an InGaAs/InGaAsP heterostructure grown by metal-organic chemical vapor deposition lattice matched to an $n$-type (100) InP substrate. The undoped active region of the heterostructure consists of five 5.5-nm-thick $\mathrm{In}_{0.53} \mathrm{Ga}_{0.47}$ As wells, which are separated by 12 -nm-thick $\mathrm{In}_{0.76} \mathrm{Ga}_{0.24} \mathrm{As}_{0.53} \mathrm{P}_{0.47}$ barriers. Optical confinement is provided first by 50 -nm-thick $\operatorname{In}_{0.81} \mathrm{Ga}_{0.19} \mathrm{As}_{0.42} \mathrm{P}_{0.58}$ layers, and then by 80 -nm-thick $\operatorname{In}_{0.90} \mathrm{Ga}_{0.10} \mathrm{As}_{0.23} \mathrm{P}_{0.77}$ layers. The upper cladding is a $1.5-\mu \mathrm{m}$-thick InP layer doped with $7 \times 10^{17} \mathrm{~cm}^{-3}$ of $\mathrm{Zn}$, while the lower cladding is a $1.0-\mu \mathrm{m}$-thick InP layer doped with $3 \times 10^{18} \mathrm{~cm}^{-3}$ of Si. The heterostructure has been fabricated into ridge-guided lasers with $3-\mu \mathrm{m}$ ridge width and $400-\mu \mathrm{m}$ cavity length. The facets of the quantum-well and the quantum-dash lasers are all unpassivated. At room temperature, they typically exhibit a threshold current $I_{\mathrm{TH}}$ of $22 \mathrm{~mA}$, an emission wavelength of $1600 \mathrm{~nm}$, and a two-facet slope efficiency $E_{\mathrm{SLOPE}}$ of 0.35 W/A. More details of the laser can be found in [17].

Both types of quantum-dash lasers were based on heterostructures grown on $n$-type $\left(\begin{array}{llll}1 & 0 & 0\end{array}\right) \mathrm{InP}$ substrates by molecular beam epitaxy. However, different structural designs and growth conditions resulted in different dash sizes and uniformities. The longdash heterostructure contains five layers of strained InAs dashes, each approximately 300-nm long, 25-nm wide, and 5-nm high. The density of dashes is on the order of $10^{10} \mathrm{~cm}^{2}$. With five overlapping layers, the dashes cover approximately $75 \%$ of the surface area. Each layer of dashes is embedded in a 7.6-nm-thick $\mathrm{In}_{0.64} \mathrm{Ga}_{0.16} \mathrm{Al}_{0.20}$ As well that is separated by 30 -nm-thick $\mathrm{In}_{0.50} \mathrm{Ga}_{0.22} \mathrm{Al}_{0.28}$ As barriers. In turn, the undoped dashin-well heterostructure is optically confined in 105-nm-thick $\mathrm{In}_{0.52} \mathrm{Ga}_{0.18} \mathrm{Al}_{0.30}$ As layers. The long-dash lasers have $4-\mu \mathrm{m}$ ridge width and $400-\mu \mathrm{m}$ cavity length. At room temperature, they typically exhibit a threshold current of $44 \mathrm{~mA}$, an emission wavelength of $1565 \mathrm{~nm}$, and a two-facet slope efficiency of 0.17 W/A. More details can be found in [15].

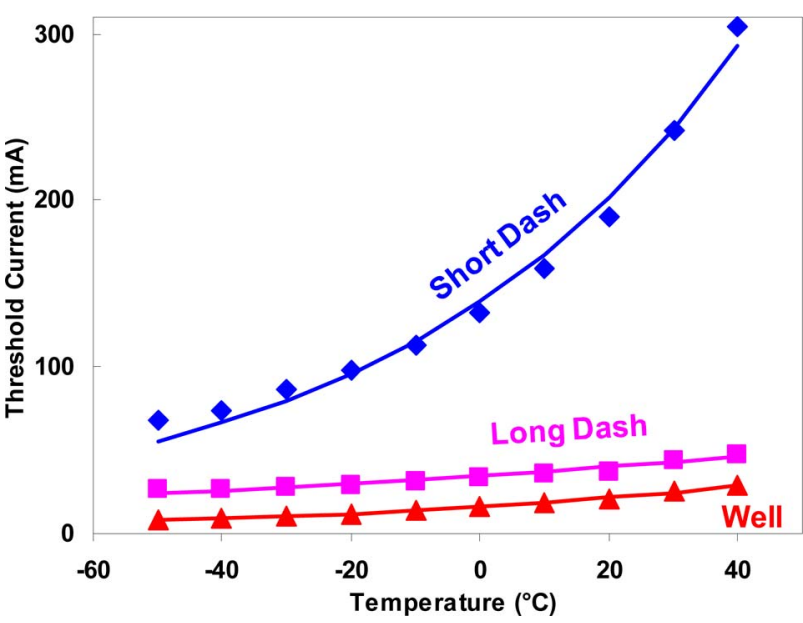

Fig. 1. Threshold current versus ambient temperature of a short-dash laser, a long-dash laser, and a quantum-well laser under pulse biases.

The short-dash heterostructure contains four layers of InAs dashes with an average height of $3 \mathrm{~nm}$ and an average width of $18 \mathrm{~nm}$. The length varies significantly from 20 to $75 \mathrm{~nm}$. The dash density is comparable to that of the long-dash heterostructure, but the area coverage is lower. Each short-dash layer is embedded in a 7.6-nm-thick $\operatorname{In}_{0.64} \mathrm{Al}_{0.2} \mathrm{Ga}_{0.16}$ As well that is separated by 30 -nm-thick $\mathrm{In}_{0.50} \mathrm{Ga}_{0.32} \mathrm{Al}_{0.18}$ As barriers. Optical confinement is provided by 160 -nm-thick $\mathrm{In}_{0.52} \mathrm{Ga}_{0.28} \mathrm{Al}_{0.2} \mathrm{As}$ above and below the active layers. The short-dash lasers have $3-\mu \mathrm{m}$ ridge width and 340- $\mu \mathrm{m}$ cavity length. They typically exhibit a threshold current of $200 \mathrm{~mA}$, an emission wavelength of $1615 \mathrm{~nm}$, and a two-facet slope efficiency of 0.09 W/A. As a result of the wide distribution of the dash sizes, the emission width can be as broad as $76 \mathrm{~nm}$ under high injection. More details can be found in [18].

Compared to the quantum-well and long-dash lasers, the short-dash laser has significantly higher threshold current and emission width. This is consistent with slower gain saturation with carrier density in quantum-dot lasers [19]. In addition to higher threshold current, the short-dash laser has stronger temperature dependence (see Fig. 1) and cannot be operated above $40{ }^{\circ} \mathrm{C}$. Therefore, the temperature characteristics of all three types of lasers were compared in the same temperature range $-50{ }^{\circ} \mathrm{C}$ to $40{ }^{\circ} \mathrm{C}$ (see Table I). The relatively high temperature stability of the long-dash laser is expected [2] for highly quantum-confined heterostructures. The relatively low temperature stability of the short-dash laser is unexpected, and may be explained by low dash uniformity and carrier confinement (see Section III). The low dash uniformity of the short-dash laser could also lead to low internal quantum efficiency and low slope efficiency. The temperature dependence of the dynamic properties of all three types of lasers is characterized in detail in the following.

\section{INTRINSIC DYNAMICS CHARACTERIZATION}

Fig. 2 illustrates the custom setup used to characterize the intrinsic laser dynamics under optical injection modulation. Unlike in electrical injection modulation, in optical injection 


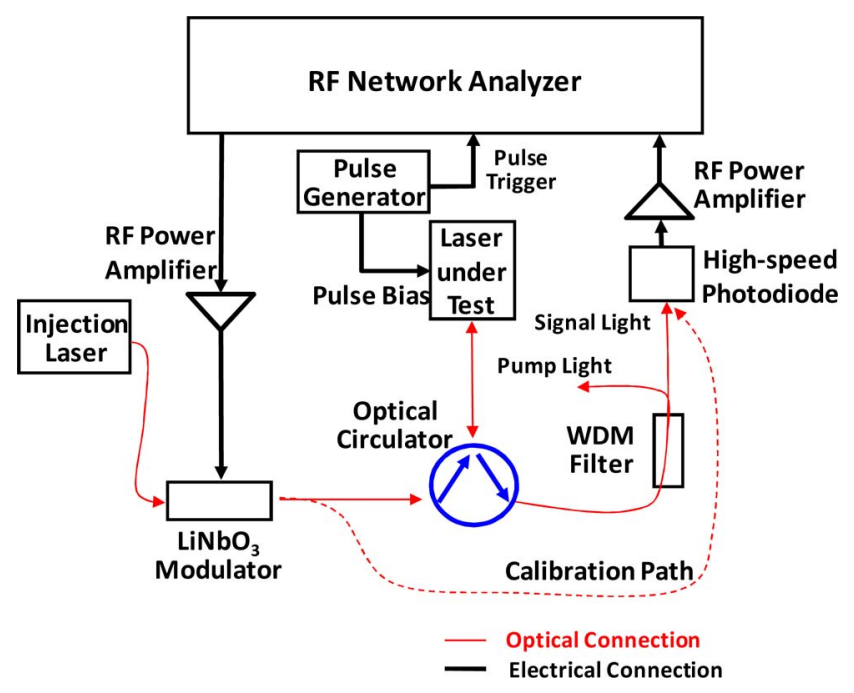

Fig. 2. Pulse optical injection modulation setup for intrinsic dynamics characterization.

modulation, the laser under test is electrically biased into lasing, but the modulation is through an optical modulator between the injection laser and the laser under test. This helps reveal the intrinsic dynamics of the laser under test without being hindered by parasitic resistances and capacitances [20] because the series resistance of quantum-dash lasers tends to be higher than that of quantum-well lasers. The present setup uses a 1310-nm narrowband laser for optical injection. Although the 1310-nm injection can excite carriers in both the dashes and their surrounding wells, due to efficient carrier exchange between the dashes and the wells, the modulation effect of the 1310-nm laser is very similar to that of a 1460-1540-nm tunable laser [21].

The injection laser is coupled to the laser under test via a $\mathrm{LiNbO}_{3}$ Mach-Zehnder modulator, an optical circulator, and a lensed fiber. The modulated emission of the laser under test is then sensed by a photodiode after using a $1560-\mathrm{nm}$ filter to eliminate the portion of the optical injection reflected by the laser under test. A time-gated two-port RF network analyzer is aided by two RF power amplifiers to modulate the optical modulator between 0.5 and $10 \mathrm{GHz}$, as well as to detect the output of the photodiode in terms of both magnitude and phase. After standard electrical calibration of the RF network, an optical fiber (see dashed line in Fig. 2) serves as the optical through to calibrate out the RF dispersions of the power amplifiers, the modulator, and the photodiode. All measured modulation responses are normalized by their values at $0.5 \mathrm{GHz}$ to eliminate the uncertainty due to variations in optical coupling efficiency.

Self-heating of the lasers under test is minimized by microsecond pulsing of both the electrical bias and the optical injection, which is a unique capability of the present setup. To this end, a pulse generator is used to bias the laser under test as well as to trigger the network analyzer after suitable delays. Typically, the laser under test is driven by a $5-\mu$ s pulse with a 200 -ns rise time and a $5 \%$ duty cycle. The RF output of the network analyzer is turned on $0.5 \mu \mathrm{s}$ after the laser under test is biased, while the RF input is sampled $2.5 \mu$ s later. All tests are performed in dry air on bare laser dies attached by conductive epoxy to a copper heat

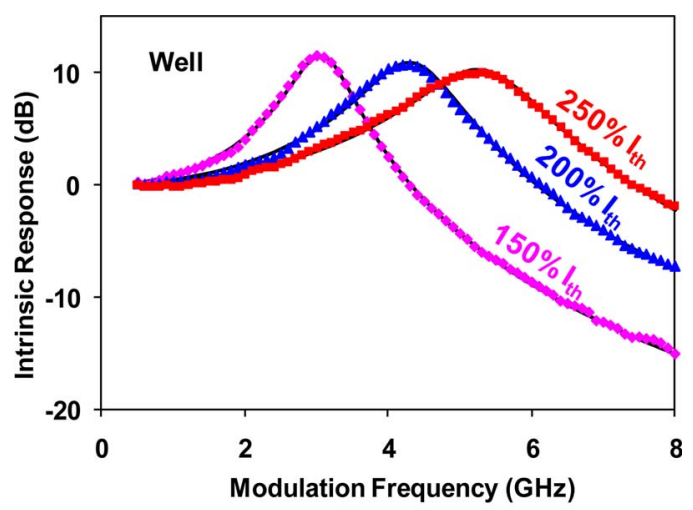

(a)

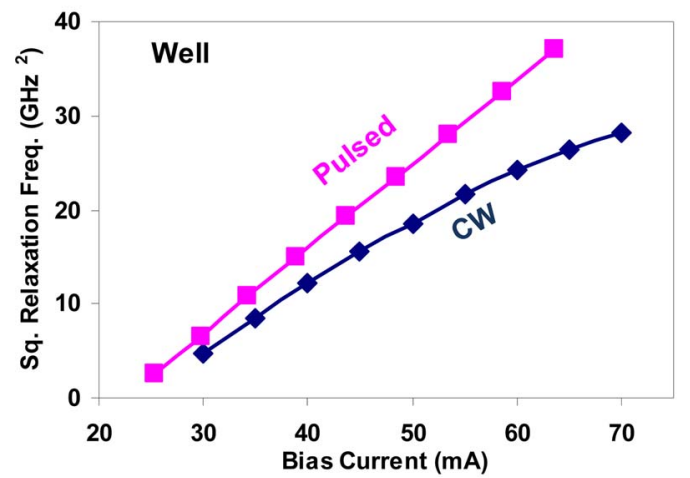

(b)

Fig. 3. (a) Measured (symbol) versus modeled (curve) intrinsic response of the quantum-well laser under different bias currents and pulse optical injection modulation. (b) Extracted bias dependence of the relaxation frequency of the quantum-well laser under $\mathrm{CW}$ and pulse optical injection modulation.

sink with $\pm 0.1{ }^{\circ} \mathrm{C}$ temperature control. For each type of laser, several devices are measured repeatedly over a course of several months to ensure that the results are representative and reproducible. This setup has been successfully used to characterize quantum-well lasers with highly consistent results [22].

Fig. 3(a) illustrates the measured modulation response of the quantum-well laser under $20^{\circ} \mathrm{C}$ and different bias currents above the threshold. It can be seen that the measured response spans a wide dynamic range with low noise, which ensures accurate extraction of dynamic properties. The measured modulation response fits very well [see Fig. 3(a)] the classic frequency dependence of quantum-well lasers [23]

$$
M(f) \propto \frac{1}{\left(f_{R}^{2}-f^{2}+j \gamma f / 2 \pi\right)}
$$

where $f_{R}$ and $\gamma$ are the relaxation frequency and the damping factor, respectively. The extracted relaxation frequency confirms that self-heating is indeed minimized in the pulse measurement. Fig. 3(b) compares the bias dependence of $f_{R}^{2}$ extracted from pulse and continuous wave (CW) measurements of a quantumwell laser. It can be seen that while $f_{R}^{2}$ tends to saturate at high currents in the $\mathrm{CW}$ measurement, it is linearly dependent on the bias current in the pulse measurement. 

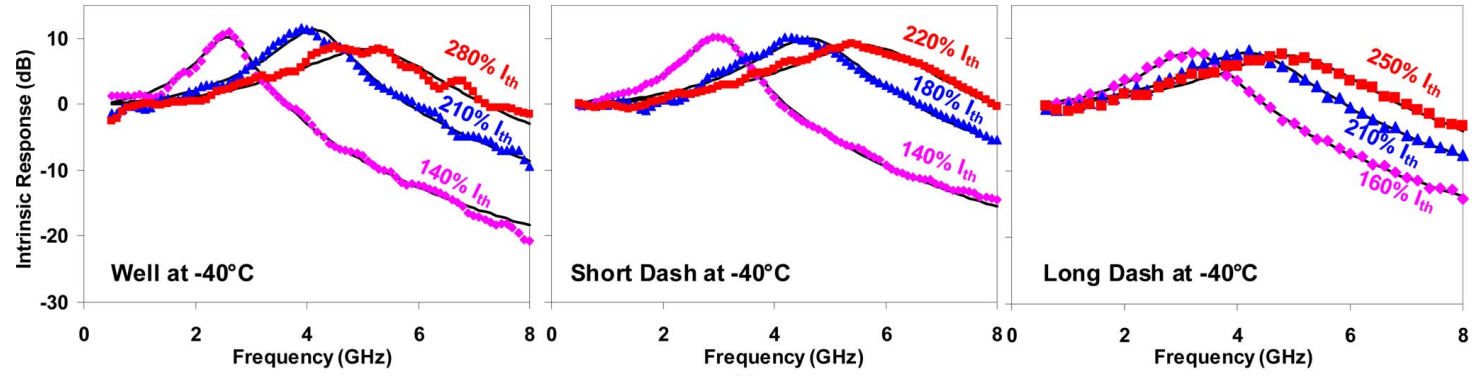

(a)
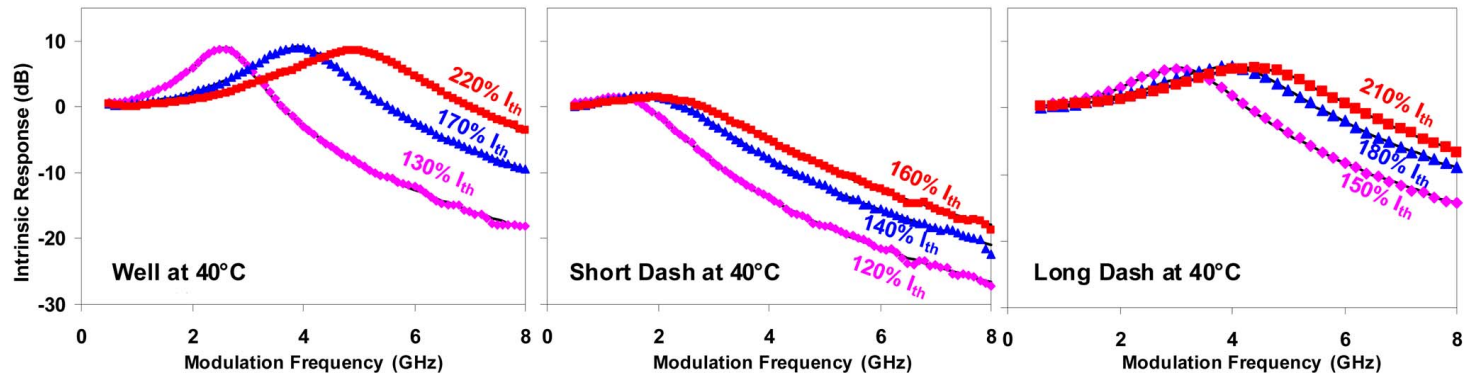

(b)

Fig. 4. Measured (symbol) versus modeled (curve) modulation response of the three types of lasers under different pulse biases and optical injection modulations at (a) $-40{ }^{\circ} \mathrm{C}$ and (b) $40{ }^{\circ} \mathrm{C}$.
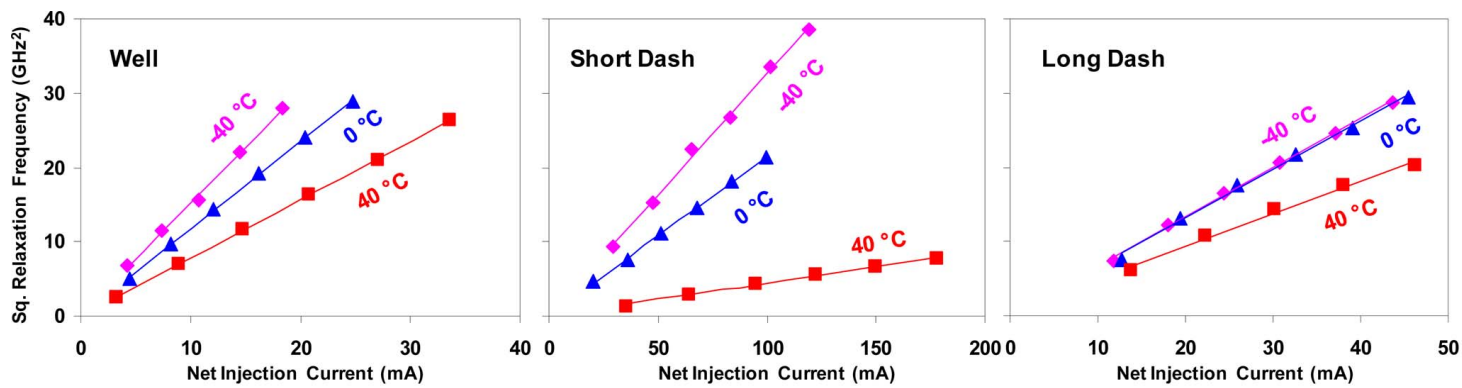

(a)
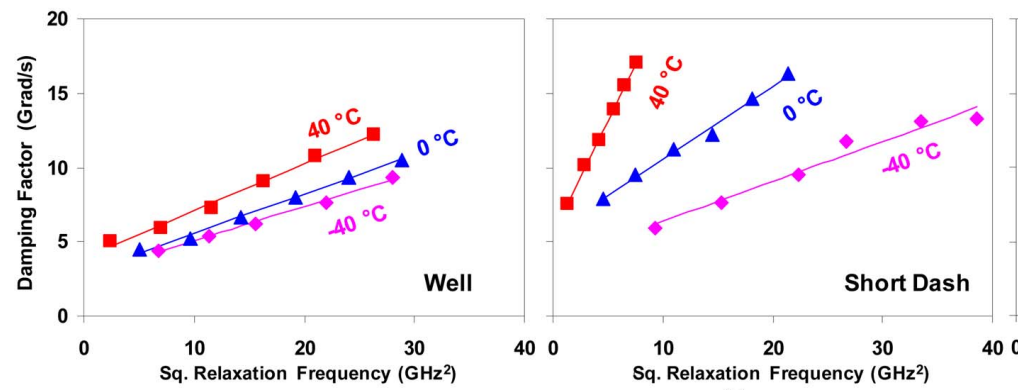

(b)

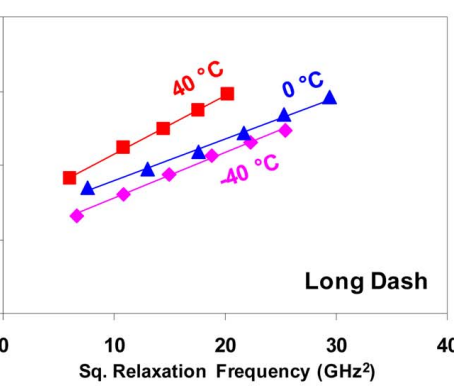

Fig. 5. Extracted (symbol) versus linearly fitted (line) relaxation frequency as a function of (a) net injection current and (b) damping factor of the three types of lasers under different ambient temperatures.

\section{Temperature EFFECTS ON INTRINSIC DyNAMICS}

Fig. 4 shows the measured modulation responses under different pulse biases and optical injection modulations at $-40^{\circ} \mathrm{C}$ and $40{ }^{\circ} \mathrm{C}$ for the three types of lasers. For negligible self-heating, the bias is limited to $300 \% I_{\mathrm{TH}}$. This also keeps the resonance peak within the 10-GHz bandwidth of the present test setup. It can be seen that the short-dash laser has stronger temperature dependence than either the quantum-well laser or the long-dash laser. Similar difference is observed at other temperatures, al- though the data are not shown to limit the length of this paper. In all cases, the frequency dependence can be fitted with (1) to accurately extract the relaxation frequency and the damping factor as a function of temperature. Fig. 5 shows that the extracted $f_{R}^{2}$ is linearly dependent on both the net injection current $I-I_{\mathrm{TH}}$ and the damping factor. The slopes of such linear dependencies can then be used to determine the modulation efficiency $E_{M}$ and the $K$ factor according to [23] as follows:

$$
f_{R}=E_{M} \sqrt{I-I_{\mathrm{TH}}}
$$




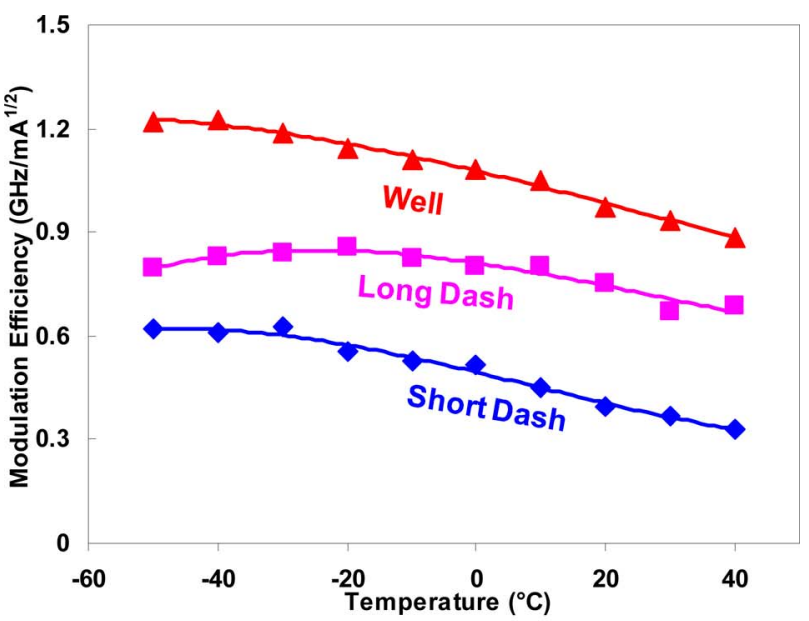

(a)

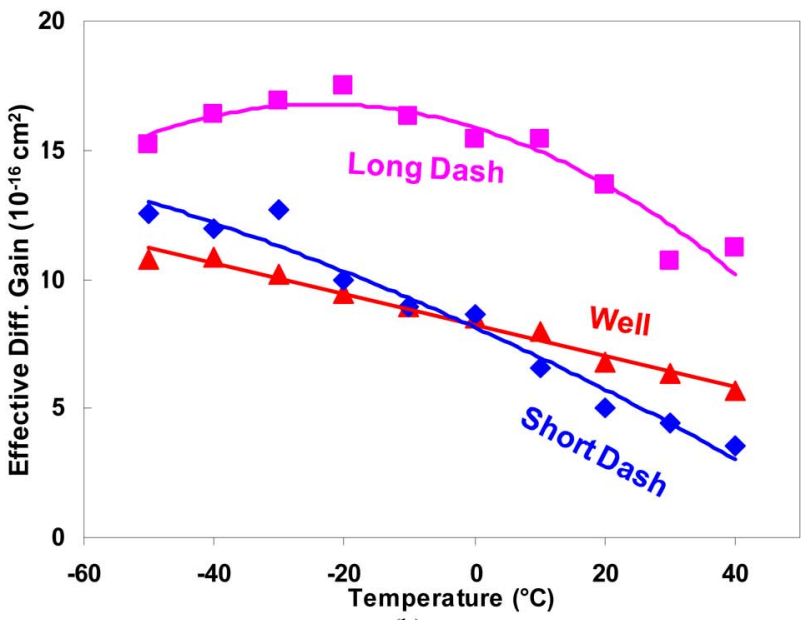

(b)

Fig. 6. Measured (symbol) versus fitted (curve) temperature dependence of (a) modulation efficiency and (b) effective differential gain.

and

$$
\gamma=K f_{R}^{2}+\frac{1}{\tau_{\mathrm{EFF}}}
$$

where $\tau_{\mathrm{EFF}}$ is the effective carrier lifetime.

Fig. 6(a) plots the extracted $E_{M}$ as a function of temperature. It can be seen that while the quantum-well laser has the highest modulation efficiency, the long-dash laser is the most stable against temperature. From the modulation efficiency and the slope efficiency, the effective differential gain $a^{\prime}$ can be calculated according to [24] as follows:

$$
a^{\prime}=\frac{4 \pi^{2} \alpha_{M}}{\alpha_{M}+\alpha_{I}} \frac{V_{\mathrm{ACT}} h \nu E_{M}^{2}}{\Gamma v_{G} E_{\mathrm{SLOPE}}}
$$

where $\alpha_{M}$ is the mirror loss, $\alpha_{I}$ is the internal loss, $V_{\mathrm{ACT}}$ is the active volume, $h \nu$ is the photon energy, is the optical confinement factor, $v_{G}$ is the group velocity, and $E_{\mathrm{SLOPE}}$ is the slope efficiency. Fig. 6(b) shows the temperature dependence of $a^{\prime}$ calculated by using the estimated parameter values listed in Table I. It can seen that in spite of very different heterostructures, $a^{\prime}$ of the quantum-dash lasers is on the same order as that of the quantum-well laser, in agreement with the theoretical prediction
[9]. In addition, while the long-dash laser is the most stable against temperature, the short-dash laser is the least stable in this temperature range.

The temperature dependence of $a^{\prime}$ could originate from the temperature dependence of the transport factor $\chi$ or the material gain $g$ because [25]

$$
a^{\prime}=\frac{1}{\chi} \frac{d g}{d N}
$$

where $N$ is the carrier density in the active region. In a dash-inwell heterostructure, $d g / d N$ could be smaller due to the much higher number of states in the well than in the dash. At elevated temperatures, the majority of the carriers would escape from the dash into the well [8], [26], thereby decreasing $d g / d N$. This could explain the steeper decrease of $a^{\prime}$ for the quantum-dash lasers than for the quantum-well laser at elevated temperatures, as well as the generally lower $a^{\prime}$ for the short-dash laser than for the long-dash laser. Another possible reason for the lower $a^{\prime}$ of the short-dash laser is its nonuniform size distribution, which would result in a wider carrier distribution and cause some dashes to cease lasing at elevated temperatures [27], [28]. Lastly, the deteriorated carrier confinement in the short-dash, as indicated by its high threshold current at elevated temperatures (see Fig. 1), would also suppress $a^{\prime}$.

The effective differential gain in conjunction with the $K$ factor can be used to extract the gain compression factor $\varepsilon$ according to [23] as follows:

$$
K=4 \pi^{2}\left(\tau_{p}+\frac{\varepsilon}{v_{G} a^{\prime}}\right)
$$

where $\tau_{P}$ is the photon lifetime estimated from the cavity length, as listed in Table I. Fig. 7 shows the temperature dependence of the extracted $K$ factor, the gain compression factor, and the effective carrier lifetime. It can be seen in Fig. 7(a) that for the quantum-well laser, the $K$ factor slightly increases with increasing temperature. Combined with the slight decrease of its effective differential gain [see Fig. 6(b)], it results in a nearly temperature-independent gain compression factor $\varepsilon$, as shown in Fig. 7(b). Similarly, the long-dash laser has nearly temperatureindependent $K$ factor, effective differential gain, and gain compression factor, as expected. In comparison, the short-dash laser exhibits strong temperature dependence in its $K$ factor, effective differential gain, and gain compression factor.

Fig. 7(b) shows that for both the long-dash and short-dash lasers, the gain compression factor is approximately twice that of the quantum-well laser, which appears to be the main reason the quantum-dash lasers have narrower modulation bandwidth than the quantum-well laser. The study on semiconductor optical amplifiers has attributed [19] the difference in the gain compression factor to the difference in carrier-heating mechanisms. Specifically, carrier heating is dominated by free-carrier absorption in quantum dashes, but by stimulated transition in quantum wells. This can also explain the stronger temperature dependence of the gain compression factor of the short-dash laser because its much higher threshold current and higher carrier density would lead to stronger carrier heating by free-carrier absorption. Lastly, carrier heating by free-carrier absorption could be stronger in the 


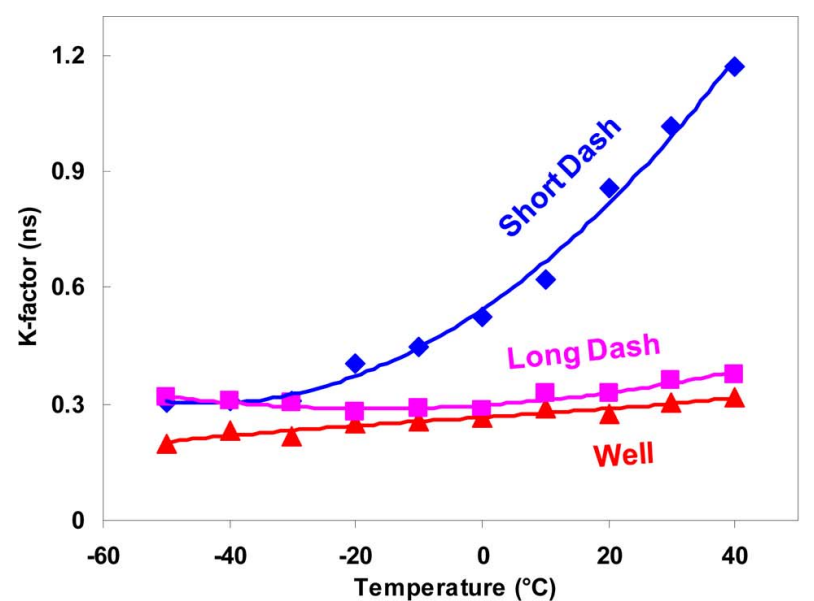

(a)

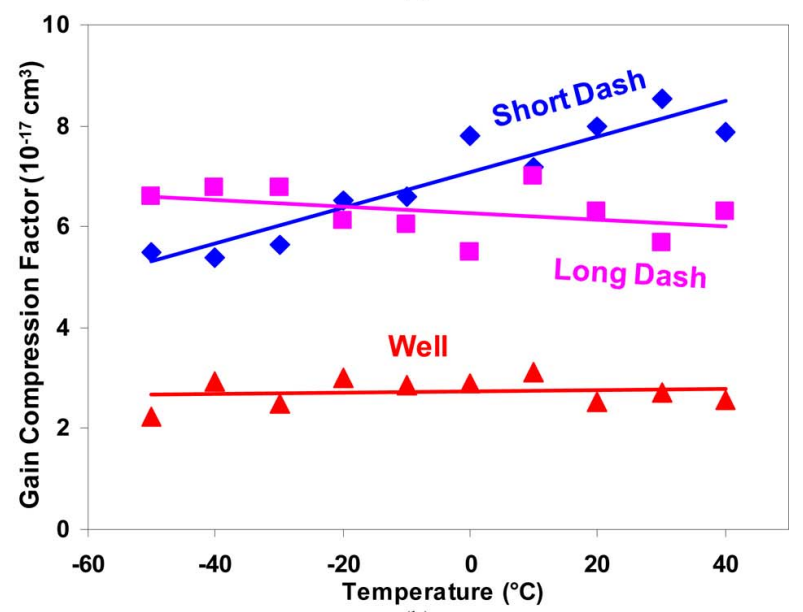

(b)

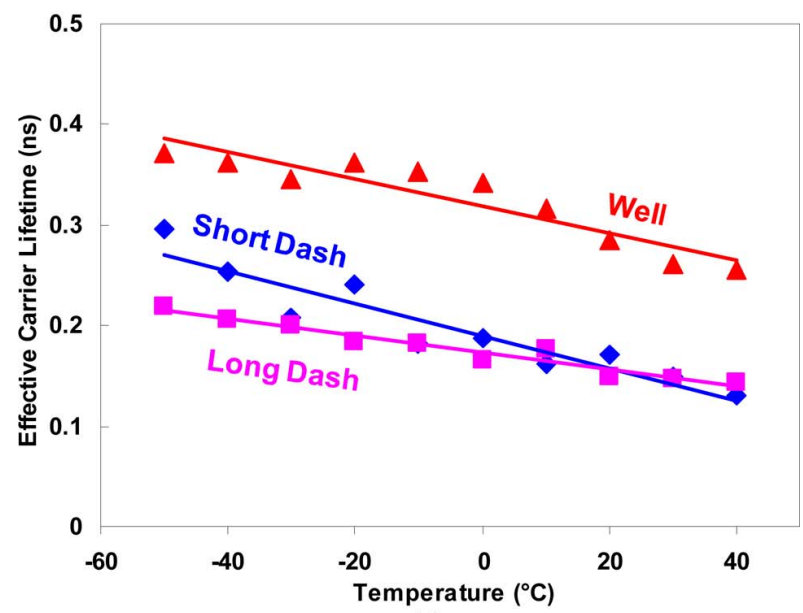

(c)

Fig. 7. Extracted (symbol) and fitted (curve) temperature dependence of (a) $K$ factor, (b) gain compression factor, and (c) effective carrier lifetime.

quantum dashes simply due to the difference in the properties of InAlGaAs and InGaAsP.

It can be seen from Fig. 7(c) that while the effective carrier lifetimes of the all three lasers decrease with increasing temperature, the effective carrier lifetimes of both quantum-dash lasers are approximately half of that of the quantum-well laser.
This implies that Auger recombination [29] dominates carrier recombination in all three lasers, while defect-related recombination [30] introduces additional temperature dependence in the short-dash laser due to its larger surface-to-volume ratio.

\section{CONCLUSION}

Compared to quantum-well lasers, the present quantum-dash lasers have comparable effective differential gain but approximately twice the gain compression factor, probably due to carrier heating by free-carrier absorption as opposed to stimulated transition. Therefore, the narrower modulation bandwidth of the quantum-dash lasers appears to be mainly limited by the gain compression factor.

As expected, the long-dash laser exhibits higher temperature stability than the quantum-well laser. However, the short-dash laser exhibits lower temperature stability, probably due to its higher surface-to-volume ratio and nonuniform dash sizes. Since short and nonuniform dashes are required for its broadband emission [5], careful tradeoff must be considered between its emission and modulation characteristics.

\section{REFERENCES}

[1] R. H. Wang, A. Stintz, P. M. Varangis, T. C. Newell, H. Li, K. J. Malloy, and L. F. Lester, "Room-temperature operation of InAs quantum-dash lasers on InP (001)," IEEE Photon. Technol. Lett., vol. 13, no. 8, pp. 767-769, Aug. 2001.

[2] R. Schwertberger, D. Gold, J. P. Reithmaier, and A. Forchel, "Longwavelength InP-based quantum-dash lasers," IEEE Photon. Technol. Lett., vol. 14, no. 6, pp. 735-737, Jun. 2002.

[3] J. P. Reithmaier, A. Somers, S. Deubert, R. Schwertberger, W. Kaiser, A. Forchel, M. Calligaro, P. Resneau, O. Parillaud, S. Bansropun, M. Krakowski, R. Alizon, D. Hadass, A. Bilenca, H. Dery, V. Mikhelashvili, G. Eisenstein, M. Gioannini, I. Montrosset, T. W. Berg, M. VanDer Poel, J. Mork, and B. Tromborg, "InP based lasers and optical amplifiers with wire-/dot-like active regions," J. Physics D, pp. 2088-2102, 2005.

[4] A. Somers, W. Kaiser, J. P. Reithmaier, A. Forchel, M. Gioaninni, and I. Montrosset, "Optical gain properties of InAs/InAlGaAs/InP quantum dash structures with a spectral gain bandwidth of more than $300 \mathrm{~nm}$," Appl. Phys. Lett., vol. 89, no. 6, pp. 061107-1-061107-3, 2006.

[5] B. S. Ooi, H. S. Djie, Y. Wang, C. -L. Tan, J. C. M. Hwang, X.-M. Fang, J. M. Fastenau, A. W. K. Liu, G. T. Dang, and W. H. Chang, "Quantum dashes on InP substrate for broadband emitter applications," IEEE J. Sel. Topics Quantum Electron., vol. 14, no. 4, pp. 1230-1238, Jul./Aug. 2008.

[6] S. Hein, V. von Hinten, W. Kaiser, S. Hofling, and A. Forchel, "Dynamic properties of $1.5 \mu \mathrm{m}$ quantum dash lasers on (100) InP," Electron. Lett., vol. 43, no. 20, pp. 1093-1095, 2007.

[7] F. Lelarge, B. Dagens, J. Renaudier, R. Brenot, A. Accard, F. van Dijk, D. Make, O. L. Gouezigou, J.-G. Provost, F. Poingt, J. Landreau, O. Drisse, E. Derouin, B. Rousseau, F. Pommereau, and G.-H. Duan, "Recent advances on InAs/InP quantum dash based semiconductor lasers and optical amplifiers operating at $1.55 \mu \mathrm{m}$," IEEE J. Sel. Topics Quantum Electron., vol. 13, no. 1, pp. 111-124, Jan./Feb. 2007.

[8] H. Dery and G. Eisenstein, "Self-consistent rate equations of self-assembly quantum wire lasers," IEEE J. Quantum Electron., vol. 40, no. 10, pp. 1398-1409, Oct. 2004.

[9] A. Markus and A. Fiore, "Modeling carrier dynamics in quantum-dot lasers," Phys. Statica Solidei (A), vol. 201, no. 2, pp. 338-344, 2004.

[10] H. Dery and G. Eisenstein, "The impact of energy band diagram and inhomogeneous broadening on the optical differential gain in nanostructure lasers," IEEE J. Quantum Electron., vol. 41, no. 1, pp. 26-35, Jan. 2005.

[11] Z. Mi and P. Bhattacharya, "DC and dynamic characteristics of P-doped and tunnel injection $1.65-\mu \mathrm{m}$ InAs quantum-dash lasers grown on InP (001)," IEEE J. Quantum Electron., vol. 42, no. 12, pp. 1224-1232, Nov. 2006. 
[12] B. Dagens, D. Make, F. Lelarge, B. Rousseau, M. Calligaro, M. Carbonnelle, F. Pommereau, A. Accard, F. Poingt, L. Le Gouezigou, C. Dernazaretian, O. Le Gouezigou, J. G. Provost, F. van Dijk, P. Resneau, M. Krakowski, and G. H. Duan, "High bandwidth operation of directly modulated laser based on quantum-dash InAs-InP material at $1.55 \mu \mathrm{m}$," IEEE Photon. Technol. Lett., vol. 20, no. 11, pp. 903-905, Jun. 2008.

[13] O. Kjebon, R. Schatz, S. Lourdudoss, S. Nilsson, B. Stalnacke, and L. Backbom, "30 GHz direct modulation bandwidth in detuned loaded InGaAsP DBR lasers at $1.55 \mu$ m wavelength," Electron. Lett., vol. 33, no. 6, pp. 488-489, 1997

[14] F. Grillot, N. A. Naderi, M. Pochet, C.-Y. Lin, and L. F. Lester, "Variation of the feedback sensitivity in a $1.55 \mu \mathrm{m}$ InAs/InP quantum-dash FabryPerot semiconductor laser," Appl. Phys. Lett., vol. 93, no. 19, pp. 1911081-191108-3, 2007.

[15] N. A. Naderi, M. Pochet, F. Grillot, N. Terry, V. Kovanis, and L. F. Lester, "Modeling the injection-locked behavior of a quantum dash semiconductor laser," IEEE J. Sel. Topics Quantum Electron., vol. 15, no. 3, pp. 563-571, May/Jun. 2009.

[16] Y. Tanaka, M. Ishida, K. Takada, T. Yamamoto, H. Song, Y. Nakata, M. Yamaguchi, K. Nishi, M. Sugawara, and Y. Arakawa, "25 Gbps direct modulation in 1.3- $\mu \mathrm{m}$ InAs/GaAs high-density quantum dot lasers," in Proc. Dig. Conf. Lasers Electro-Optics, May, 2010, pp. 1-2, Paper CTuZ1.

[17] V. Aimez, J. Beauvais, J. Beerens, D. Morris, H. S. Lim, and B.S. Ooi, "Low-energy ion-implantation-induced quantum-well intermixing," IEEE J. Sel. Topics Quantum Electron., vol. 8, no. 4, pp. 870-879, Jul./.Aug. 2002.

[18] H. S. Djie, C. L. Tan, B. S. Ooi, J. C. M. Hwang, X. M. Fang, Y. Wu, J. M. Fastenau, W. K. Liu, G. T. Dang, and W. H. Chang, "Ultrabroad stimulated emission from quantum-dash laser," Appl. Phys. Lett., vol. 91, no. 11, pp. 111116-1-111116-3, 2007.

[19] A. J. Zilkie, J. Meier, M. Mojahedi, P. J. Poole, P. Barrios, D. Poitras, T. J. Rotter, C. Yang, A. Stintz, K. J. Malloy, P. W. E. Smith, and J. S. Aitchison, "Carrier dynamics of quantum-dot, quantum-dash, and quantum-well semiconductor optical amplifiers operating at $1.55 \mu \mathrm{m}$," IEEE J. Quantum Electron., vol. 43, no. 11, pp. 982-991, Nov./Dec. 2007.

[20] C. B. Su, J. Eom, C. H. Lange, C. B. Kim, R. B. Lauer, W. C. Rideout, and J. S. Lacourse, "Characterization of the dynamics of semiconductorlasers using optical modulation," IEEE J. Quantum Electron., vol. 28, no. 1, pp. 118-127, Jan. 1992.

[21] C. Chen, S. Halder, B. S. Ooi, and J. Hwang, "Intrinsic response of quantum dash lasers under optical modulation," in Proc. IEEE Laser Electro-Optics Soc. Annu. Meeting, 2008, pp. 471-472.

[22] C. Chen, H. S. Djie, Y. H. Ding, B. S. Ooi, J. C. M. Hwang, and V. Aimez, "Fundamental and dynamic properties of intermixed InGaAsInGaAsP quantum-well lasers," IEEE J. Quantum Electron., vol. 46, no. 9, pp. 1368-1374, Sep. 2010.

[23] T. Keating, X. Jin, S. L. Chuang, and K. Hess, "Temperature dependence of electrical and optical modulation responses of quantum-well lasers," IEEE J. Quantum Electron., vol. 35, no. 10, pp. 1526-1534, Oct. 1999.

[24] Y. Matsui, H. Murai, S. Arahira, Y. Ogawa, and A. Suzuki, "Enhanced modulation bandwidth for strain-compensated InGaAlAs-InGaAsP MQW lasers," IEEE J. Quantum Electron., vol. 34, no. 10, pp. 1970-1978, Oct. 1998.

[25] R. Nagarajan, M. Ishikawa, T. Fukushima, R. S. Geels, and J. E. Bowers, "High-speed quantum-well lasers and carrier transport effects," IEEE J. Quantum Electron., vol. 28, no. 10, pp. 1990-2008, Oct. 1992.

[26] D. G. Deppe and D. L. Huffaker, "Quantum dimensionality, entropy, and the modulation response of quantum dot lasers," Appl. Phys. Lett., vol. 77, no. 21, pp. 3325-3327, Nov. 2000.

[27] D. G. Deppe, S. Freisem, H. Huang, and S. Lipson, "Electron transport due to inhomogeneous broadening and its potential impact on modulation speed in p-doped quantum dot lasers," J. Phys. D: Appl. Phys., vol. 38, no. 13, pp. 2119-2125, Jul. 2005

[28] D. G. Deppe and H. Huang, "Fermi's golden rule, nonequilibrium electron capture from the wetting layer, and the modulation response in P-doped quantum-dot lasers," IEEE J. Quantum Electron., vol. 42, no. 3, pp. 324 330, Mar./Apr. 2006.

[29] J. Minch, S. H. Park, T. Keating, and S. L. Chuang, "Theory and experiment of $\mathrm{In}_{1-\mathrm{x}} \mathrm{Ga}_{\mathrm{x}} \mathrm{As}_{\mathrm{y}} \mathrm{P}_{1-\mathrm{y}}$ and $\mathrm{In}_{1-\mathrm{x}-\mathrm{y}} \mathrm{Ga}_{\mathrm{x}} \mathrm{Al}_{\mathrm{y}}$ As long-wavelength strained quantum-well lasers," IEEE J. Quantum Electron., vol. 35, no. 5, pp. 771782, May 1999.

[30] I. P. Marko, S. J. Sweeney, A. R. Adams, S. R. Jin, B. N. Murdin, R. Schwertberger, A. Somers, J. P. Reithmaier, and A. Forchel, "Recombination mechanisms in InAs/InP quantum dash lasers studied using high hydrostatic pressure," Phys. Statica Solidei (B), vol. 241, no. 14, pp. 3427-3431, 2004.

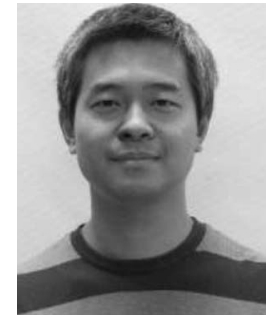

Cheng Chen ( $\left.\mathrm{S}^{\prime} 06\right)$ received the B.S. degree in physics from Wuhan University, Wuhan, China, in 2002, and the M.S. degree in electrical engineering from Chinese Academy of Sciences, Beijing, China, in 2005 . He is currently working toward the Ph.D. degree in electrical and computer engineering at Lehigh University, Bethlehem, PA.

$\mathrm{He}$ is also with RF Micro Devices Inc., Greensboro, $\mathrm{NC}$, where he is responsible for the development of pseudomorphic-HEMT-based RF switches. His research interests include characterization and modeling of quantum-dot/ quantum-dash lasers and GaAs-based HBTs.

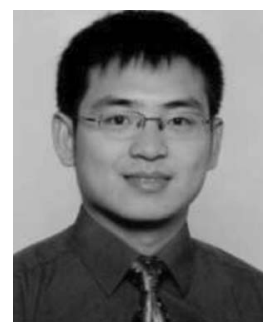

Yang Wang (S'04-M'08) received the B.S. degree from the University of Science and Technology of China, Hefei, China, in 2002, the M.S. degree from National University of Singapore (under the Singapore-MIT Alliance), Singapore, in 2003, and the Ph.D. degree in electrical engineering from Lehigh University, Bethlehem, PA, in September 2007.

From 2003 to 2007, he was a Research Associate at the Center for Optical Technologies, Lehigh University, where he designed, fabricated, and characterized novel photonic integrated circuits using quantum-dot intermixing and InP-based quantum-dash lasers. He is currently a Device Engineer at OptiComp Corporation, Zephyr Cove, NV, where he is involved in research and development of vertical-cavity surface-emitting laser, semiconductor optical amplifier (SOA), $\mathrm{p}-\mathrm{i}-\mathrm{n}$, and integrated wavelength division multiplexing module. He is currently a Principal Investigator of several small business innovation research (SBIR) Phase II and Phase III projects sponsored by U.S. Air Force in OptiComp. He has authored over 50 international technical papers.

Dr. Wang is an active member of the International Society for Optical Engineering and Sigma Xi Scientific Research Society.

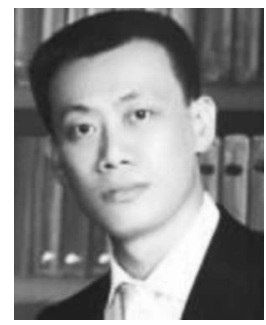

Hery Susanto Djie (S'03-M'04) received the B.Eng. (first class honors) degree in electrical engineering from Pelita Harapan University, Tangerang, Indonesia, in 1999, under Lippo Group Scholarship, and the $\mathrm{Ph} . \mathrm{D}$. degree from the Electrical Engineering Department, Nanyang Technological University, Singapore, in January 2004.

Later, he joined Agilent Technologies, Singapore, where he was in charge of the development of highbrightness LEDs. From 2004 to 2007, he was a Research Scientist at the Center for Optical Technologies, Lehigh University, Bethlehem, PA, where he was a key contributor in the technology and development of quantum-dot bandgap engineering and semiconductor broadband emitter. Since February 2007, he has been a Development Engineer at JDS Uniphase Corp., San Jose, CA, where he is engaged in highvolume manufacturing of high power laser diode, high-speed semiconductor laser, widely tunable semiconductor laser, optical add-drop multiplexer, and photonic integrated circuits. He is the author or coauthor of more than 180 published international technical papers with several U.S. patents pending in the field of monolithic integration of photonic devices, quantum-dot and quantum-wel intermixing, semiconductor laser, and broadband semiconductor light source.

Dr. Djie is a member of International Society for Optical Engineering, Materials Research Society (MRS), and Sigma Xi Scientific Research Society. 


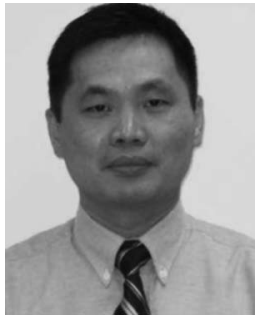

Boon S. Ooi (M'95-SM'03) received the B.Eng. and $\mathrm{Ph} . \mathrm{D}$. degrees in electronics and electrical engineering from the University of Glasgow, U.K., in 1992 and 1994, respectively

From 1996 to 2000, he was an Assistant Professor at Nanyang Technological University, Singapore. From 2003 to 2009, he was an Associate Professor at Lehigh University, Bethlehem, PA. He is currently a Professor of Electrical Engineering at King Abdullah University of Science and Technology, Thuwal, Saudi Arabia. His current research interests include the development of semiconductor photonics integrated circuits, and quantumdot and quantum-dash laser devices.

Dr. Ooi was a Vice President of Phosistor Technologies, Inc., Pleasanton, CA, from 2000 to 2003. He is a Fellow of the International Society for Optical Engineering and the Institute of Physics.

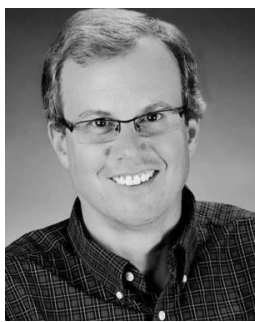

Luke F. Lester (SM'01) received the B.S. degree in engineering physics and the Ph.D. degree in electrical engineering from Cornell University, Ithaca, NY, in 1984 and 1992, respectively.

Since 1994, he has been the University of New Mexico (UNM), Albuquerque, NM, where is currently a Professor in the Department of Electrical and Computer Engineering, Endowed Chair Professor in Microelectronics, and General Chair of the Optical Science and Engineering Graduate Program. He was an Engineer at the General Electric Electronics Laboratory, Syracuse, NY, for six years, where he was involved in research on high electron mobility transistors for millimeter-wave applications. In all, he has 25 years of experience in III-V semiconductor devices and advanced fabrication techniques. In 2001, he was a cofounder and Chief Technology Officer of Zia Laser, Inc., a startup company using quantum-dot laser technology to develop products for communications and computer/microprocessor applications. The company was later acquired by Innolume, $\mathrm{GmbH}$. He is the author or coauthor of more than 100 published journal articles and over 120 conference papers.

Dr. Lester is an active organizer and participant in the IEEE Photonics Society's conferences, workshops, and journals. He was a U.S. Air Force Summer Faculty Fellow in 2006 and 2007. His awards and honors include the 1998 UNM School of Engineering Research Award, the 1994 Martin Marietta Manager's Award, and the 2007 UNM ECE Teaching Award.
Thomas L. Koch (M'88-F'95) received the B.A. degree in physics from Princeton University, Princeton, NJ, in 1977 and the Ph.D. degree in applied physics from the California Institute of Technology, Pasadena, in 1982.

He currently holds the Daniel E. ' 39 and Patricia M. Smith Endowed Chair of Director, Center for Optical Technologies, and is a joint Professor in Electrical and Computer Engineering and Physics, Lehigh University, Bethlehem, PA. Previously he held Vice President positions at SDL, Lucent, and most recently at Agere Systems, where he was responsible for research and development of the underlying materials and device technologies required to support Agere's optoelectronic and IC product portfolio. He has authored more than 300 conference and journal publications, book chapters, and books. His research activities initially focused on improving the spectral properties, modulation characteristics, and tunability of semiconductor lasers used in high capacity optical fiber communications systems. He has contributed a number of basic advances in the area of semiconductor photonic integrated circuits (PICs), which continues to be his primary research interest.

Prof. Koch has chaired numerous major international conferences and has also served on numerous conference and governance positions with IEEE LEOS. He has received the Eric E. Sumner Award from the IEEE, and the William Streifer Award for Scientific Achievement and the Distinguished Lecturer Award from the IEEE LEOS. He is a Fellow of Bell Labs, the Optical Society of America, and a member of the National Academy of Engineering.

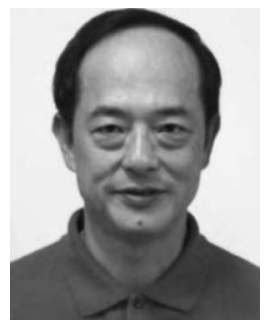

James C. M. Hwang (M'81-SM'82-F'94) received the B.S. degree in physics from National Taiwan University, Taipei, Taiwan, in 1970, and the M.S. and $\mathrm{Ph} . \mathrm{D}$. degrees in materials science from Cornell University, Ithaca, NY, in 1976 and 1978, respectively.

After being with IBM, ATT, GE, and GAIN, he joined Lehigh University, Bethlehem, PA, as a Professor of Electrical Engineering and the Director of Compound Semiconductor Technology Laboratory, in 1988. His current research interests include MEMS, microwave transistors and integrated circuits, lasers, and photodetectors.

Dr. Hwang received the IBM Faculty Award in 2007. 